\title{
Characterization of Behavioral Symptoms of Older Adults with Neurocognitive Disorder by the Report of Informal Caregivers
}

\author{
Yara Luana Pereira Souza ${ }^{1}$ \\ Andreia Schmidt ${ }^{1}$
}

\begin{abstract}
Behavioral symptoms of people with dementia can negatively affect the mental health of informal caregivers. The aims of this study were to describe the behavioral symptoms of adults diagnosed with dementia based on the report of their caregivers and to characterize the caregivers regarding the level of hope, burden and stress related to care. Twenty informal caregivers participated in the study, with an average age of 54 years, predominantly daughters and wives of the patients, who granted an interview and responded to instruments regarding burden and stress, hope, patient's characteristics and behavioral problems. Despite a high level of hope, the participants had a burden level compatible with that of caregivers of chronic patients. The most mentioned challenging behaviors were difficulties in carrying out activities of daily living and aggressiveness, predominantly characterized as behavioral excesses. We emphasize the importance of interventions with caregivers of people with neurocognitive disorder, oriented to the management of challenging behaviors.
\end{abstract}

Keywords: behavior disorders, dementia, caregivers, old age

\section{Caracterização de Sintomas Comportamentais de Adultos Mais Velhos com Transtorno Neurocognitivo pelo Relato de Cuidadores Informais}

\begin{abstract}
Resumo: Sintomas comportamentais de pessoas com demência podem impactar negativamente a saúde mental de cuidadores informais. Os objetivos do presente estudo foram descrever os sintomas comportamentais de adultos com diagnóstico de demência pelo relato de seus cuidadores e caracterizar os cuidadores informais entrevistados em relação ao nível de esperança, sobrecarga e estresse relacionados ao cuidado. Participaram 20 cuidadoras informais, com idade média de 54 anos, predominantemente filhas e esposas dos pacientes, que responderam a uma entrevista e a instrumentos sobre sobrecarga e estresse, esperança, características dos pacientes e problemas de comportamento. Apesar de um alto nível de esperança, as participantes tinham nível de sobrecarga compatível com o de cuidadores de pacientes crônicos. Os comportamentos mais citados foram dificuldades de realização de atividades de vida diária e agressividade, caracterizados predominantemente como excessos comportamentais. Ressalta-se a importância de intervenções com cuidadores de pessoas com transtorno neurocognitivo, orientadas para o manejo de comportamentos desafiadores.
\end{abstract}

Palavras-chave: distúrbios do comportamento, demência, cuidadores, velhice

\section{Caracterización de Síntomas Conductuales de Adultos Mayores con Trastorno Neurocognitivo Según el Informe de Cuidadores Informales}

\begin{abstract}
Resumen: Los síntomas comportamentales de personas con demencia pueden impactar negativamente a la salud mental de sus cuidadores informales. En este estudio se pretende describir los síntomas comportamentales de adultos con diagnóstico de demencia mediante el relato de sus cuidadores y caracterizar a los cuidadores informales entrevistados en términos de nivel de esperanza, sobrecarga y estrés relacionados con el cuidado. Participaron 20 cuidadoras informales, edad promedio: 54 años, predominantemente hijas y esposas de los pacientes, que respondieron a una entrevista y a instrumentos sobre sobrecarga y estrés, esperanza, características de los pacientes y problemas de comportamiento. A pesar del alto nivel de esperanza, las participantes presentaron un nivel de sobrecarga compatible con el de cuidadores de pacientes crónicos. Los comporta4mientos más citados fueron dificultades en la ejecución de actividades cotidianas y agresividad, caracterizados predominantemente como excesos comportamentales. Se resalta la importancia de intervenciones con los cuidadores de personas con trastorno neurocognitivo orientadas al manejo de comportamientos desafiadores.
\end{abstract}

Palabras clave: transtornos de la conducta, demencia, cuidadores, vejez

\footnotetext{
${ }^{1}$ Universidade de São Paulo, Ribeirão Preto-SP, Brazil

This research is part of the scientific program of Instituto Nacional de Ciência e Tecnologia sobre Comportamento, Cognição e Ensino (INCT-ECCE), funded by Conselho Nacional de Pesquisa (CNPq, Process 465686/2014-1) and by Fundação de Amparo à Pesquisa do Estado de São Paulo (FAPESP, Process 2014/50909-8). A CAPES scholarship (cod. 001) is granted to the first author.

Correspondence address: Andreia Schmidt. Universidade de São Paulo. Av. Bandeirantes, 2900, Ribeirao Preto-SP, Brazil. CEP. 14040-900. E-mail: aschmidt@ffclrp.usp.br
}

About 10 million people develop dementia per year worldwide, and the number of people affected by the disease is expected to be about 152 million by 2050 (World Health Organization [WHO], 2017). Approximately $60 \%$ of individuals with dementia live in low- and middle-income countries, but as life expectancy in these countries has grown, it is estimated that this proportion will increase to about $72 \%$ by 2050 (Patterson, 2018). In these countries, almost all individuals with dementia live in their own homes, 
predominantly depending on informal care provided by close relatives, usually women (Aires et al., 2020; Patterson, 2018).

Informal care for people with Major Neurocognitive Disorder - MND (American Psychiatric Association [APA], 2013), which includes all dementias, has been described as a chronic experience of stress (Allen et al., 2017). This experience results in burden for the caregiver, causing physical and psychological health problems such as high rates of stress, frailty, anguish, and depression (Jesus, Orlandi, \& Zazzetta, 2018; Martins et al., 2019). The burden of informal caregivers has been related to several factors, ranging from the need to reconcile the role of caring with some formal work (Barham, Pinto, Andrade, Lorenzini, \& Ferreira, 2015), the lack of correct information and guidance on care practices (Jesus et al., 2018) to the patient's clinical condition and level of dependence and the decrease in quality of life due to the increased workload (Cesário, Leal, Marques, \& Claudino 2017).

In addition to these factors, the presence of behavioral and psychological symptoms of dementia (BPSD), also known as neuropsychiatric symptoms of dementia, is related to increased caregiver's burden (Allen et al., 2017) and is a strong predictor of patient's institutionalization (Feast, MonizCook, Stoner, Charlesworth, \& Orrell, 2016). BPSDs include psychotic symptoms (such as delusions and hallucinations), agitation, aggressive behaviors, depression and anxiety, apathy, disinhibition, appetite problems, repetitive motor behaviors, and nocturnal restlessness (Kales, Gitlin, \& Lyketsos, 2015). Several factors are associated with the causes of BPSD, ranging from those related to the person herself (neurobiological factors, personality traits and previous psychiatric illnesses, among others) to environmental factors and those related to the provided care. The interaction between these factors can aggravate BPSD (Kales et al., 2015).

The investigation of these behaviors has been carried out, overall, by standardized inventories (e.g., the Neuropsychiatric Inventory Questionaire [NPI-Q], Kaufer et al., 2000) that analyze the presence or absence of BSPD and, eventually, the perception of caregivers about their difficulty in dealing with these symptoms. The behaviors evaluated in each instrument vary, with some behaviors being evaluated more than others. Although these instruments safely survey the main and most common BPSD, providing important data to know the extent of its impact on the mental health of caregivers, they provide few opportunities for caregivers to spontaneously report behaviors that, from their point of view, are the most difficult to handle. Furthermore, the variety of symptoms that can be exhibited in each category has been little investigated, and this variety can be important in determining the caregiver's perception of its greater or lesser severity and in planning interventions.

In addition to the description of behaviors deemed problematic by caregivers, a type of classification that can help to understand BPSD concerns the concepts of behavioral deficit and excess, developed by behavior analysts in the context of the study on disruptive behaviors (Kanfer \& Saslow, 1965). Some authors have used this classification to assess behavioral difficulties presented by older people with dementia (AllenBurge, Stevens, \& Burgio, 1999), which is based on the principle that environmental factors influence the frequency and intensity of many symptoms associated with MND (Trahan, Kahng, Fisher, \& Hausman, 2011), and their classification may help to identify the variables on which these behaviors can be a function. The terms "behavioral excess" and "behavioral deficit" refer to the frequency or intensity with which a behavior is displayed above or below that required by a given situation, which makes the behavior to be considered as inappropriate for a certain situation. This classification can help to understand whether caregivers have more difficulty handling with behavioral deficits or excesses, which is relevant for implementing interventions that meet the needs of caregivers.

The objectives of the present study were to describe the behavioral symptoms of adults diagnosed with dementia as reported by their caregivers and to characterize the participants concerning the level of hope, burden, and stress related to care.

\section{Participants}

\section{Method}

Twenty women, informal caregivers of older adults with dementia, participated in this study. The patients cared for were both women and men, diagnosed with MND (e.g., Alzheimer's disease, frontotemporal dementia, etc.). All the participants were primary caregiver at least four days a week, or for at least 20 hours a week, and did not receive remuneration for this activity. The study inclusion criteria were: being the main caregiver of the person with MND, providing care for at least four days a week or 20 hours a week, and not receiving remuneration for this activity. Exclusion criteria were: not having enough information about the routine of the person being cared for. Data collection took place at the Outpatient Clinic of Geriatrics and Dementia (GEDEM) of Hospital de Clínicas da Faculdade de Medicina de Ribeirão Preto - USP, São Paulo, Brazil.

\section{Instruments}

A semi-structured interview script prepared by the researchers was used, consisting of 18 questions regarding six topics. The general theme of the interview was the caregiver's routine in patient care as well as difficulties encountered in the activity and the problem behaviors presented by the patients. The questions referred to the daily routine, investigating the conditions in which the behavioral difficulties reported by the caregiver occurred.

The Caregiver Burden Scale (CBS) (Medeiros, Ferraz, Quaresma, \& Menezes, 1998) was used to assess the burden and stress of caregivers of older people. The scale consists of 22 items that assess "general tension," "isolation," "disappointment," "emotional involvement," and "environment," arranged in a frequency scale ranging from "never," "rarely," "sometimes," and "often," with scores ranging from 1 to 4 , respectively. The total score can range from 22 to 88 . The higher the total score for each variable, the greater the burden regarding the assessed items. The instrument was adapted and validated for the Brazilian context by Medeiros et al. (1998), with the intra- and interobserver reproducibility coefficient being 0.87 and 0.92 respectively. 
The Herth Hope Index (Sartore \& Grossi, 2008) was used, which assesses the caregivers' level of hope by 12 items that must be evaluated as "strongly disagree," "disagree," "agree," and "strongly agree." Scores range from 12 to 48, considering that the higher the score, the higher the level of hope. The scale was adapted and validated for the Brazilian context by Sartore and Grossi (2008). Reliability was verified by Cronbach's alpha coefficient $(0.83)$, with similar value $(\mathrm{rho}=0.97)$ for the test-retest.

The Lawton-Brody Instrumental Activities of Daily Living Scale (adapted and validated for the Brazilian context by Santos \& Virtuoso Júnior, 2008) was applied to assess the performance of the older adults in instrumental activities of daily living such as using the telephone and preparing meals. It contains seven items on instrumental activities, with scores ranging from 1 (does not have the habit or is inept to perform the task) to 3 (being able to perform the task without assistance). The results are evaluated by the sum of the points, with up to 7 points corresponding to total dependence; between 7 and 21 points, partial dependence; and 21 points corresponding to independence. The adaptation and validation presented a significant reproducibility (0.89) and objectivity (0.80) index, which demonstrate acceptable reliability indices.

The Mini-Mental State Examination (MMSE), a cognitive tracking instrument, was applied to assess temporal and spatial orientation, word registration, attention, calculation, word recall, language, and visual ability. The scores range from 0 , considered the highest degree of impairment, to 30, representing a greater cognitive capacity. The cutoff points vary depending on the patient's level of education: 28 points for 9 to 11 years of education; 26, for 5 to 8 years; 25 , for 1 to 4 years; and 20 for illiterates (Brucki, Nitrini, Caramelli, Bertolucci, \& Okamoto, 2003). The MMSE data of the patients were obtained by consulting their medical records at GEDEM. As data were collected from the electronic medical record, it was not possible to determine the date of the last application of the instrument.

The Clinical Dementia Rating (CDR) (Montaño \& Ramos, 2005), a scale for assessing the level of dementia, was also used. The scale ranges from 0 (no dementia), 1 (mild dementia), 2 (moderate dementia), and 3 (severe dementia). The scale assesses memory, orientation, judgment, problem solving, community issues, household chores, entertainment activities, and self-care. The patients' CDR data were obtained by consulting their medical records at GEDEM. The CDR was adapted to the Brazilian context by Montaño and Ramos (2005) and showed sensitivity of $91.2 \%$ and specificity of $100 \%$, with a positive predictive value of $100 \%$ and a negative predictive value of $97.6 \%$. As data were collected from the electronic medical record, it was not possible to determine the date of the last application of the instrument.

\section{Procedures}

Data collection. Participants were approached while awaiting medical consultation for the patients they cared for, and were also informed about the objectives and procedures of the research. Those who agreed to participate in the research signed an Informed Consent Form and were taken to a private room, where the interview took place. The entire interview was recorded by an audio recorder for later transcription of the content. During the interview, participants were able to freely answer the questions proposed by the interviewer as well as deepen the topics of interest and clarify any issue. Initially, the instruments CBS, Hope Index, and Lawton-Brody Scale were applied. Subsequently, the interview was conducted. At the end of the interview, the participants were led back to the waiting room. In order to avoid delays in medical appointments, the participants invited to participate in the survey were the last on the list of appointments for the day. Thus, the interview took place before the consultation, without harming the participants or the functioning of the outpatient clinic.

Data analysis. The results of the standardized instruments were assessed according to their propositions and transferred to spreadsheets of the JASP program version 0.10.2.0. Scores were organized using descriptive statistics of mean and standard deviation.

The interviews were transcribed and the problem behaviors reported by the participants were categorized in relation to their nature (behavioral excess or deficit, as defined by Kanfer \& Saslow, 1965) and to the area in which they occurred. After categorization, the percentage of episodes that fit into each category was estimated.

Behaviors reported as problematic by caregivers were classified into five categories. The first category, described as "Activities of daily living," included the problem behaviors related to the patient's performance of daily activities, with the subcategories feeding (e.g., refusing to eat), administration of medication (e.g., refusing to take medicines), hygiene (e.g., wanting to take a shower at different times of the day), clothing (e.g., wearing several clothes, one over the other), and routine activities (e.g., refusing to wear a hearing aid, wandering around home overnight).

In the second category, "Neuropsychiatric symptoms," behaviors related to the presence of hallucinations and delusions were grouped as well as problems reported by caregivers due to memory failure (e.g., not remembering where to put objects or the names of people close to them). The third category, "Aggressiveness," included aggressive behaviors toward others (e.g., hitting or cursing). Aggressiveness was divided into verbal and nonverbal subcategories.

The fourth category, "Difficulties related to communication/ language," encompasses behaviors that interfered with the patient's communication with others such as inappropriate speech (e.g., courting an unknown woman); repetitive speech, and decontextualized speech (e.g., singing in the middle of a conversation). The category "Difficulties related to risk behaviors" included behaviors that had the consequence of putting their physical integrity at risk (e.g., forgetting the stove on, going out alone and getting lost). Finally, the category "Others" included reports of behavior problems that did not fit into the other categories such as urinary incontinence, difficulties in swallowing, and restless sleep.

All problem behaviors were also classified as behavioral deficits or excesses. Behavioral excesses were deemed as 
behaviors displayed by the older adult at a frequency greater than that considered appropriate, and/or with an intensity beyond adequate, or even inappropriate, such as refusing to take medication. Behavioral deficits were deemed as those with low or no frequency and/or weak intensity, as well as the lack of display of behaviors considered adaptive such as not following instructions.

A second judge proceeded to an independent categorization of the problem behaviors reported in six interviews ( $30 \%$ of the collected material), according to the definitions of each one of the categories. The agreement index (number of agreements divided by the sum of agreements and disagreements, multiplied by 100 ) was $93.2 \%$, considering the classification of behavioral excesses and deficits and the categorization of difficulties.

\section{Ethical Considerations}

This research was approved by the Research Ethics Committee of Faculdade de Filosofia, Ciências e Letras de Ribeirão Preto da Universidade de São Paulo, CAAE No. 85417818.2.0000.5407, Opinion No. 2.847.177.

\section{Results}

All 20 participants were women, aged between 17 and 75 years $(M=54.4$ years, $S D= \pm 5.5)$, but most of them $(85 \%)$ aged between 40 and 68 years. These caregivers were mostly daughters $(50 \%)$ or wives of the patients $(25 \%)$ and had paid works in addition to providing care $(45 \%)$ or were retired $(40 \%)$. The mean level of education of the group was 8.5 years $(S D= \pm 6.6)$; 13 caregivers had up to eight years of education $(65 \%)$ and the others had high school or college degrees (12 years or more of education). The mean time of patient care was eight and a half years (between 1 and 22 years $-S D= \pm 6.6$ ). The people cared for were mostly women $(75 \%)$, aged between 65 and 93 years $(M=77.1$ years, $S D= \pm 8.4)$. The mean time since diagnosis was 7.5 years $(S D= \pm 5.5)$. Most of these patients were diagnosed with Alzheimer's Disease (40\%) or Mixed Dementia (30\%).

The results of the participants on the CBS and Hope Index, as well as the scores of the older adults on the CDR, MMSE and Lawton-Brody Scale can be verified in Table 1.

According to Table 1, on the CBS (Burden and Stress) scale, caregivers had a mean total score of 53.2, with the highest score in the General Tension subcategory $(=2.70)$ and the lowest score in the Environment subcategory $(=1.83)$. On the Hope Index, the participants had a mean score of 39.3 out of 48 possible points.

The patients' mean CDR score was 1.47 , indicating that they had, on average, moderate dementia. The mean score of patients on the MMSE was 17.1. The evaluation of the MMSE test score is carried out according to the individual's level of education. In this sample, participants had different levels of education, therefore, different cutoff scores. The mean score obtained in this study classifies older adults in this sample as cognitively impaired at all levels of education. On the Lawton-Brody Scale, the mean score was 11.3 , with three older people (15\%) being fully dependent and 17 (85\%) being partially dependent.

Participants reported 258 occurrences of problem behaviors presented by the patients they cared for - on average, 12.9 occurrences per interview. The distribution of these behaviors among the categories adopted for analysis is presented in Table 2.

Table 1

Mean and Standard Deviation of Participants'Scores on the Burden Scale, Hope Index, and Older Adults'Scores on the MMSE, IADL, and CDR Instruments

\begin{tabular}{|c|c|c|c|c|c|c|}
\hline \multicolumn{7}{|c|}{ Caregivers } \\
\hline \multicolumn{6}{|c|}{ Burden } & \multirow[t]{2}{*}{ Hope } \\
\hline & Tension & Isolation & Disappointment & Emotional Involvement & Environment & \\
\hline Mean & 2.70 & 2.19 & 2.11 & 2.26 & 1.83 & 39.33 \\
\hline$S D$ & 0.86 & 1.16 & 0.58 & 0.99 & 1.83 & 5.89 \\
\hline \multicolumn{7}{|c|}{ Older adults } \\
\hline & MMSE & IADL & CDR & & & \\
\hline Mean & 17.12 & 11.35 & 1.47 & & & \\
\hline$S D$ & 5.81 & 3.70 & 0.79 & & & \\
\hline
\end{tabular}

Note. MMSE = Mini Mental State Examination; IADL = Instrumental Activities of Daily Living; CDR = Clinical Dementia Rating. 
Table 2

Categories, Frequencies and Classifications of Problem Behaviors Reported by Caregivers

\begin{tabular}{|c|c|c|c|c|c|}
\hline \multirow[t]{2}{*}{ Category } & \multirow[t]{2}{*}{ Subcategories } & \multicolumn{2}{|c|}{ Frequency } & \multicolumn{2}{|c|}{ Classification } \\
\hline & & $F$ & $\%$ & Deficit & Excess \\
\hline \multirow[t]{6}{*}{ Activities of Daily Living } & Medication & 18 & 7.0 & 5 & 13 \\
\hline & Food & 11 & 4.3 & 1 & 10 \\
\hline & Hygiene & 26 & 10.1 & 7 & 19 \\
\hline & Dressing themselves & 14 & 5.4 & 3 & 11 \\
\hline & Routine & 41 & 16.0 & 20 & 21 \\
\hline & Total & 110 & 42.8 & 36 & 74 \\
\hline \multirow[t]{3}{*}{ Neuropsychiatric Symptoms } & Hallucination/Delusions & 14 & 5.4 & 7 & 7 \\
\hline & Memory & 28 & 10.9 & 25 & 3 \\
\hline & Total & 42 & 16.3 & 32 & 10 \\
\hline \multirow[t]{2}{*}{ Risk behaviors } & General & 27 & 10.5 & 14 & 13 \\
\hline & Total & 27 & 10.5 & 14 & 13 \\
\hline \multirow[t]{3}{*}{ Aggressiveness } & Verbal & 31 & 12.1 & 0 & 31 \\
\hline & Nonverbal & 7 & 2.7 & 0 & 7 \\
\hline & Total & 38 & 14.8 & 0 & 38 \\
\hline \multirow[t]{4}{*}{ Communication/Language } & Inappropriate & 5 & 1.9 & 1 & 4 \\
\hline & Repetitive & 8 & 3.1 & 0 & 8 \\
\hline & Decontextualized & 9 & 3.5 & 1 & 8 \\
\hline & Total & 22 & 8.6 & 2 & 20 \\
\hline \multirow[t]{2}{*}{ Other } & General & 18 & 7.0 & 18 & 0 \\
\hline & Total & 18 & 7.0 & 18 & 0 \\
\hline \multicolumn{2}{|l|}{ Overall total } & 257 & 100 & $102(39.7 \%)$ & $155(60.3 \%)$ \\
\hline \multicolumn{2}{|c|}{ Average number of problem behaviors per interview } & \multicolumn{4}{|c|}{12.9} \\
\hline
\end{tabular}

The category of behaviors with the highest frequency of complaints was "Activities of Daily Living" (110 mentions $42.8 \%$ of the problem behaviors reported), especially behaviors related to routine (e.g., dressing themselves, eating, and taking medications), with about $16 \%$ of reports. More than half of these problem behaviors related to activities of daily living $(58 \%)$ were classified as behavioral excesses.

The second category with the greatest frequency of problem behaviors was "Neuropsychiatric symptoms" (42 occurrences, $16.3 \%$ of reports of problem behaviors). In this category, memory problems were the most reported ( $10.9 \%$ of the mentioned behaviors), and behavioral deficits were more frequent $(76 \%)$ than excesses. The category with the lowest frequency of occurrences was "Others" $(7.0 \%$ of the reports), and all these complaints were classified as behavioral deficits. This category mainly included enuresis and encopresis problems, which indicated the patients' need to wear diapers. Overall, participants reported a higher frequency of behavioral excesses $(60.3 \%)$ than behavioral deficits $(39.7 \%)$.

\section{Discussion}

The profile of the participants (middle-aged women, daughters or wives of patients, with less than 8 years of education, low-income, retired or with triple work hours) is compatible with that verified in low- and middle-income countries, such as Brazil, where informal care for people with MND is predominantly carried out by women (Aires et al., 2020; Alves et al., 2019). The accumulation of activities for these women and the growing need for patients' care increase the likelihood of burden among these caregivers, as reported in the literature (Carvalho \& Neri, 2019).

Patients with MND have an increasing level of impairment (physical and cognitive), which increases their functional impairment (APA, 2013) and requires more time and effort from the caregiver to assist the patient in performing daily activities such as preparing their meals, leaving the house, or doing small household chores. In the sample of the present study, patients had, on average, a moderate level of dependence and cognitive impairment, suggesting that most of them required monitoring from caregivers to perform various activities of daily living. In this sense, the care of people with MND has been related, in the literature, to a chronic experience of stress (Allen et al., 2017), which is also common among caregivers of people with other long-term illnesses, contributing to the experience of burden. Authors of a research on caregivers of patients with chronic diseases found a level of burden and general stress similar to that found in this study, in addition to a moderate level of general tension (Yildiz, Karakas, Güngörmüs, \& Cengiz, 2017). 
These results indicate that the studied sample of caregivers presents burden levels compatible with those of caregivers of other chronic patients, but also justifies the fact that the area of activities of daily living was mentioned as the one with the highest frequency among the patients' problem behaviors. This finding suggests that most of the behavior problems presented by patients with MND are displayed in daily activities (therefore, with high frequency), which can be an important source of stress and burden for their caregivers.

In the literature, there is still no consensus on which behavioral problems have the greatest impact on caregivers' quality of life. Feast et al. (2016) found that loss of communication skills, memory loss, and aggressiveness, in addition to incontinence and irritability, significantly impact the quality of life of caregivers. A research carried out by Ferri and Ames (2004) in 11 countries in Latin America (including Brazil), China, Taiwan, and India found that, in Latin America, the behavioral problem most mentioned by caregivers was that of vocal disorders, followed by "other behaviors" (therefore, behaviors not included in the applied instrument). In a research conducted in Canada, the most reported problems were those related to memory/attention, followed by problems with daily activities, sleep, and spatial orientation (Kilik et al., 2008). This variability of results indicates that cultural factors, in addition to the financial resources of caregivers, are likely to influence the caregivers' assessment of the behavior problems presented by the patients. Furthermore, the type of applied instrument, whether more or less broad or detailed, can also interfere in the type of caregivers' report and in the conclusions of the studies. In this research, the authors chose to collect spontaneous information from the participants about the behaviors that bothered them in the people they cared for. This does not mean that other problem behaviors were not displayed, but rather that the reported ones were those that bothered them the most. Clearly identifying the behavioral problems of people with MND that most interfere with routine care is essential for planning effective interventions capable of reducing the burden resulting from long-term care.

Another important result observed in this research is that, overall, the report of behavioral excesses was more frequent than that of behavioral deficits. The behavioral excesses most frequently reported as difficult to handle were those related to activities of daily living (refusal to have hygiene practices and take medication, and compliance with routines), verbal aggression, and excesses in communication (inappropriate and decontextualized speeches). The most mentioned deficits were those related to memory, risk behaviors, and enuresis and encopresis problems (others). One of the difficulties in dealing with behavioral excesses may be related to the idea of care and health on the part of caregivers, who understand "health" as performing tasks independently (Rodrigues, Watanabe, \& Derntl, 2006). Being unhealthy, therefore, implies needing help to carry out activities, and care becomes synonymous with performing the tasks that are difficult for older adults to perform for them and not with them. In this case, caregivers seem to be more prepared to deal with behavioral deficits, which may explain why deficits were less mentioned by caregivers than excesses. Conversely, this perception can be dysfunctional when it comes to behavioral excesses, as the problem is precisely the behavior displayed by the older adult with intensity and/or frequency higher than expected.

Behavioral excesses require caregivers to handle with challenging behaviors (e.g., dealing with inappropriate social behavior or the patient's aggressive behavior), which, in turn, requires them to identify the variables of the physical and social environment that favor their occurrence (Trahan et al., 2011). Overall, behavioral excesses are functional in nature, but their occurrence is clearly influenced by environmental and social variables that evoke excessive responses in terms of frequency and intensity (Kanfer \& Saslow, 1965). For instance, the defensive behavior of a person in the face of a threat to their physical integrity is considered an appropriate behavior. However, this same behavior is deemed aggressive when exhibited outside of a "threatening" context. A person with MND may present an aggressive response (hitting) in front of a family member who wants to help them bathe, which can be considered a behavioral excess. The patients, however, may interpret the situation as that of a stranger trying to take off their clothes (a threatening context). Dealing with this type of behavior requires the caregiver to identify that, when the family member is not recognized by the patient, help is seen as a threat and can trigger an aggressive reaction. Nevertheless, according to Trahan et al., this type of observation repertoire is uncommon among caregivers, who tend to attribute to the disease the cause of problematic behaviors in older people with MND rather than to environmental and social variables. Thus, behaviors that could be prevented (such as aggressiveness in the aforementioned example) start being addressed as MND symptoms, without efficiently handling with the situation.

The analysis of challenging behaviors in terms of behavioral excesses and deficits is common in other populations who also tend to consider excesses more problematic than deficits (Schutte et al., 2018). Nonetheless, interventions focused on behavioral excesses are less studied than those focused on handling with deficits, with recent efforts to change this reality (Shiri, Pouretemad, Fathabadi, \& Narimani, 2020). In the case of interventions with people with MND, these studies are even rarer, which indicates the need for greater investment in conducting research on this topic. Considering that the behavior problems of people with MND are important predictors of their institutionalization and the burden for caregivers (Feast et al., 2016), interventions that help caregivers to identify variables that favor their occurrence and keep them in the repertoire of the patient and the caregivers' themselves (Trahan et al., 2011) can be important strategies to prevent institutionalization.

Despite the burden rates observed among the caregivers of this research and the fact that MND is a progressive disease with no prospect of cure, a high level of hope was verified among the participants, with scores similar to those found in other studies on caregivers (Pavarini et al., 2018). This high level of hope is probably not related to a possible cure, but rather to the possibility that, in the future, the stressful situation of care will improve, which is an indicator of positive coping with the difficulties encountered by caregivers. The presence of this good level of hope can indicate a willingness to face difficult and challenging 
situations, contributing to the well-being of individuals despite the encountered difficulties (Souza et al., 2017).

It should be noted that this study has some limitations. The first concerns the small number of participants and the fact that all of them attend a specific outpatient clinic for people with MND. It is a tertiary outpatient clinic, whose population has characteristics that demand highly specialized care, which may differ from the general population. This suggests that the present results must be weighted according to the specific characteristics of this sample. Future research should endeavor to investigate the occurrence of behavioral problems in larger and representative samples from different regions of the country. In addition, it is important to survey the coping strategies adopted by caregivers to handle with the behavior problems of their relatives, aiming to identify specific intervention needs of this population and ways to implement these interventions.

We identified a high frequency of complaints about the behavior of people diagnosed with MND based on the reports of their informal caregivers, especially with regard to activities of daily living. These complaints especially referred to behavioral excesses, which demand specific handling by the caregiver. Relations between the caregivers' burden, the patients' degree of dependence, and the frequency of exhibited problem behaviors should be further investigated. Our results are relevant insofar as they show that the main difficulties encountered by the caregivers are related to the handling of everyday situations such as eating, bathing, or taking medication. According to common sense, memory loss is highlighted as the main symptom related to dementias, but this study shows that problems related to the handling of routine activities can be as hard as or even more difficult for caregivers to overcome. These results indicate the need to develop specific interventions regarding these topics for caregivers of people with MND. It is well known that nonpharmacological strategies should be the first therapeutic plan to be implemented for handling with behavior problems. The data obtained from this study may help future research aimed at developing interventions for this population. Interventions must focus on meeting the demands for handling with problem behaviors in this population, and analyses based on excesses and deficits can be useful in their planning.

\section{References}

Aires, M., Fuhrmann, A. C., Mocellin, D., Dal Pizzol, F. L. F., Sponchiado L. F., Marchezan, C. R., ... Paskulin, L. M. G. (2020). Burden of informal caregivers of dependent elderlies in the community in small cities. Revista Gaúcha de Enfermagem, 41(spe), e20190156. doi:10.1590/1983-1447.2020.20190156

Allen, A. P., Curran, E. A., Duggan, A., Cryan, J. F., Chorcoráin, A. N., Dinan, T. G., ... Clarke, G. (2017). A systematic review of the psychobiological burden of informal caregiving for patients with dementia: Focus on cognitive and biological markers of chronic stress. Neuroscience \& Biobehavioral Reviews, 73, 123-164. doi:10.1016/j.neubiorev.2016.12.006
Allen-Burge, R., Stevens, A. B., \& Burgio, L. D. (1999). Effective behavioral interventions for decreasing dementia-related challenging behavior in nursing homes. International Journal of Geriatric Psychiatry, 14(3), 213-228. doi:10.1002/(SICI)10991166(199903)14:3<213::AID-GPS974>3.0.CO;2-0

Alves, B. S., Oliveira, A. S., Santana, E. S., Chaves, R. N., Marinho, M. S., \& Reis, L. A. (2019). Caracterização dos cuidadores informais de idosos dependentes quanto aos aspectos sociodemográficos e de saúde [Characterization of the informal caregivers of dependente elderly according the sociodemographic and health aspects]. Revista de Saúde Coletiva da UEFS, 9, 113-118. doi:10.13102/ rscdauefs.v9i0.3684

American Psychiatric Association. (2013). Diagnostic and statistical manual of mental disorders: DSM-5 (5th ed.). Washington, DC: Author.

Barham, E. J., Pinto, F. N. F. R., Andrade, A. R., Lorenzini, M. F. J., \& Ferreira, C. R. (2015). Fundamentos e estratégias de intervenção para a promoção de saúde mental em cuidadores de idosos [Fundamentals and intervention strategy for the promotion of mental health in elderly caregivers]. In S. G. Murta, C. Leandro-França, K. B. Santos, \& L. Polejack (Orgs.), Prevenção e promoção em saúde mental: Fundamentos, planejamento e estratégias de intervenção [Prevention and promotion in mental health: Fundamentals, planning and intervention] (pp. 844-862). Novo Hamburgo, RS: Synopsys.

Brucki, S., Nitrini, R., Caramelli, P., Bertolucci, P. H. F., \& Okamoto, I. H. (2003). Sugestões para o uso do mini-exame do estado mental no Brasil [Suggestions for utilization of the mini-mental state examination in Brazil]. Arquivos de Neuro-Psiquiatria, 61(3B), 777781. doi:10.1590/S0004-282X2003000500014

Carvalho, E. B., \& Neri, A. L. (2019). Patterns of use of time by family caregivers of elderly persons with dementia. Revista Brasileira de Geriatria e Gerontologia, 22(1), e180143. doi:10.1590/1981-22562019022.180143

Cesário, V.A. C., Leal, M. C. C., Marques, A. P. O., \& Claudino, K. A. (2017). Estresse e qualidade de vida do cuidador familiar do idoso portador da doença de Alzheimer [Stress and quality of life of the family caregivers of elderly with Alzheimer's disease]. Saúde em Debate, 41(112), 171182. doi:10.1590/0103-1104201711214

Feast, A., Moniz-Cook, E., Stoner, C., Charlesworth, G., \& Orrell, M. (2016). A systematic review of the relationship between behavioral and psychological symptoms (BPSD) and caregiver well-being. International Psychogeriatrics, 28(11), 1761-1774. doi:10.1017/S1041610216000922

Ferri, C. P., \& Ames, D. (2004). Behavioral and psychological symptoms of dementia in developing countries. International Psychogeriatrics, 16(4), 441459. doi:10.1017/S1041610204000833 
Jesus, I. T.M., Orlandi,A.A. S., \& Zazzetta, M. S. (2018). Burden, profile and care: Caregivers of socially vulnerable elderly persons. Revista Brasileira de Geriatria e Gerontologia, 2l(2), 194-204. doi:10.1590/1981-22562018021.170155

Kales, H. C., Gitlin, L. N., \& Lyketsos, C. G. (2015). Assessment and management of behavioral and psychological symptoms of dementia. BMJ (Clinical Research Ed.), 350, h369. doi:10.1136/bmj.h369

Kanfer, F. H., \& Saslow, G. (1965). Behavioral analysis: An alternative to diagnostic classification. Archives of General Psychiatry, 12(6), 529-538. doi:10.1001/ archpsyc.1965.01720360001001

Kaufer, D. I., Cummings, J. L., Ketchel, P., Smith, V., MacMillan, A., Shelley, T., ... DeKosky, S. T. (2000). Validation of the NPI-Q, a brief clinical form of the neuropsychiatric inventory. The Journal of Neuropsychiatry and Clinical Neurosciences, 12(2), 233239. doi:10.1176/jnp.12.2.233

Kilik, L. A., Hopkins, R. W., Day, D., Prince, C. R., Prince, P. N., \& Rows, C. (2008). The progression of behavior in dementia: An in-office guide for clinicians. American Journal of Alzheimer's Disease \& Other Dementias, 23(3), 242-249. doi:10.1177/1533317507313676

Martins, G., Corrêa, L., Caparrol, A. J. S., Santos, P. T. A., Brugnera, L. M., \& Gratão, A. C. M. (2019). Sociodemographic and health characteristics of formal and informal caregivers of elderly people with Alzheimer's Disease. Escola Anna Nery, 23(2), e20180327. doi:10.1590/2177-9465-ean-2018-0327

Medeiros, M. M. C., Ferraz, M. B., Quaresma, M. R., \& Menezes, A. P. (1998). Adaptação ao contexto cultural brasileiro e validação do "Caregiver Burden scale" [Adaptation and validation of the caregiver burden scale to Brazilian cultural milieu]. Revista Brasileira de Reumatologia, 38(4), 193-199.

Montaño, M. B. M. M., \& Ramos, L. R. (2005). Validity of the Portuguese version of Clinical Dementia Rating. Revista de Saúde Pública, 39(6), 912-917. doi:10.1590/ S0034-89102005000600007

Patterson, C. (2018). World Alzheimer report 2018. The state of the art of dementia research: New frontiers. London, United Kingdom: Alzheimer's Disease International.

Pavarini, S. C. I., Brigola, A. G., Ottaviani, A. C., Luchesi, B. M., Souza, E. N., Rossetti, E. S., ... Tavares Neto, R. F. (2018). Factors associated with cognitive performance in elderly caregivers. Arquivos de Neuro-Psiquiatria, 76(10), 685-691. doi:10.1590/0004-282x20180101
Rodrigues, S. L. A., Watanabe, H. A. W., \& Derntl, A. M. (2006). A saúde de idosos que cuidam de idosos [The health of the elderly that care for elders]. Revista Escola de Enfermagem da USP, 40(4), 493-500. doi:10.1590/ S0080-62342006000400007

Santos, R. L., \& Virtuoso Júnior, J. S. (2008). Confiabilidade da versão brasileira da escala de atividades instrumentais da vida diária [Realiability of the Brazilian version of the scale of instrumental activities of daily living]. Revista Brasileira em Promoção da Saúde, 21(4), 290-296. doi:10.5020/18061230.2008.p290

Sartore, A. C. S., \& Grossi, S. A. A. (2008). Escala de Esperança de Herth: Instrumento adaptado e validado para a língua portuguesa [Herth Hope index: Instrument adapted and validated to portuguese]. Revista da Escola de Enfermagem da USP, 42(2), 227-232. doi:10.1590/ S0080-62342008000200003

Schutte, C., Richardson, W., Devlin, M., Hill, J., Ghossainy, M., \& Hewitson, L. (2018). The relationship between social affect and restricted and repetitive behaviors measured on the ADOS-2 and maternal stress. Journal of Autism and Developmental Disorders, 48(3), 751-758. doi:10.1007/s10803-017-3453-1

Shiri, E., Pouretemad, H., Fathabadi, J., \& Narimani, M. (2020). A pilot study of family-based management of behavioral excesses in young Iranian children with autism spectrum disorder. Asian Journal of Psychiatry, 47, 101845. doi:10.1016/j.ajp.2019.101845

Souza, E. N., Oliveira, N. A., Luchesi, B. M., Gratão, A. C. M., Orlandi, F. S., \& Pavarini, S. C. I. (2017). Relationship between hope and spirituality of elderly caregivers. Texto \& Contexto-Enfermagem, 26(3), e6780015. doi:10.1590/0104-07072017006780015

Trahan, M. A., Kahng, S., Fisher, A. B., \& Hausman, N. L. (2011). Behavior-analytic research on dementia in older adults. Journal of Applied Behavior Analysis, 44(3), 687691. doi:10.1901/jaba.2011.44-687

World Health Organization. (2017). Dementia: Number of people affected to triple in next 30 years. Retrieved from https://www.who.int/news/item/07-12-2017-dementianumber-of-people-affected-to-triple-in-next-30-years

Yildiz, E., Karakas, S. A., Güngörmüs, Z., \& Cengiz, M. (2017). Levels of care burden and self-efficacy for informal caregiver of patients with cancer. Holistic Nursing Pratica, 31(1), 7-15. doi:10.1097/ HNP.0000000000000185 
Yara Luana Pereira Souza is a Master's candidate of the Graduate Program in Psychobiology, Universidade de São Paulo, Ribeirão Preto-SP, Brazil.

Andreia Schmidt is an Associate Professor from Universidade de São Paulo, Ribeirão Preto-SP, Brazil.

Authors' Contribution:

All authors made substantial contributions to the conception and design of this study, data analysis and interpretation, and the manuscript revision and approval of the final version. All authors are responsible for the manuscript content.

Associate Editor:

Fabio Scorsolini-Comin

Received: Oct. 25, 2020

1st Revision: Mar. 03, 2021

2nd Revision: Apr. 30, 2021

3rd Revision: Jun. 08, 2021

Approved: Jun. 11, 2021

How to cite this article:

Souza, Y. L. P., \& Schmidt, A. (2021). Characterization of behavioral symptoms of older adults with neurocognitive disorder by the report of informal caregivers. Paidéia (Ribeirão Preto), 31, e3130. doi:https://doi.org/10.1590/1982-4327e3130 